\title{
Correspondence
}

\section{Mentally disordered offenders}

Anthony Blowers in his article 'Mentally Disordered Offenders' (Psychiatric Bulletin, March 1994, 18, 166-167) recounts some of the problems he has encountered as a magistrate in securing an appropriate disposal for a mentally disordered person who came before his court. It is perhaps worthwhile to mention some of the recent developments both in central and in local services aimed at reducing the likelihood of such problems occurring and to ensure that mentally disordered people who come into contact with the criminal justice system receive care and treatment appropriate to their needs.

As Dr Blowers points out, it has long been government policy that, whenever possible, mentally disordered offenders should be cared for and treated by health and social services rather than in the criminal justice system. In part because it was apparent that this was not always being achieved, in December 1990 Ministers in the Department of Health and the Home Office established under my chairmanship a review of health and social services for mentally disordered offenders (and others requiring similar services). The review completed its work and reported to Ministers in July 1992 (Department of Health and Home Office, 1992/93).

In responding to the review, Ministers have reaffirmed their policy set out above and have endorsed a set of guiding principles put forward by the review. These are that patients/clients should be cared for and treated:

(a) with regard to the quality of care and proper attention to the needle of individuals

(b) as far as possible in the community rather than in institutional settings

(c) under conditions of no greater security than is justified by the degree of danger they present to themselves or to others

(d) in such a way as to maximise rehabilitation and their chances of sustaining an independent life

(e) as near as possible to their own homes or families if they have them.

Since the review was completed there have been several other important developments. Dr Blowers mentions that Health of the Nation (Department of Health, 1992) requires authorities to include secure and non-secure services in their strategic and purchasing plans. Further information for both health and social service authorities is available in the Health of the Nation-Mental Illness Key Area Handbook (Department of Health, 1993). In addition, services for mentally disordered offenders are now a 'first order' priority for the NHS in 1994/95. EL(93)54 requires that:

"NHS authorities should work with personal social services and criminal justice agencies to develop strategic and purchasing plans for mentally disordered offenders and similar people based on the Department of Health/ Home Office review of services. These should include:

an effective range of non-secure and secure services (including those for people with special and differing needs, such as people with learning disabilities or psychopathic disorder, ethnic minorities, young people and women)

arrangements for the multi-agency assessment and as necessary diversion of mentally disorderd offenders from the criminal justice system

meeting the health care needs of transferred or discharged prisoners

the placement, within six months, of special hospital patients who no longer require high security."

This increased priority has led to a welcome expansion of services. For instance, central capital funding of over $\$ 45$ million has been made available for medium secure psychiatric services between 1991-95 with further contributions from regional budgets. This will take the total number of medium secure places well beyond the current national target of 1,000 .

But perhaps more relevant to Dr Blowers' concerns is the great expansion of assessment and diversion schemes aiming to identify mentally disordered people who come into contact with the criminal justice system and, as appropriate, to divert them to health or social care. Such schemes may operate at magistrates court level or even earlier in the criminal justice process, e.g. at police stations. In 1990 there were only a handful of such schemes, now there are over 100 in England. Some have been assisted by Home Office funding and further bids have been invited. 
A further indication of success in ensuring more appropriate services for mentally disordered people is the greatly increased number of people transferred from prison to hospital under section 47/48 of the Mental Health Act 1983. These have risen from 337 in 1990 to 755 in 1993.

Dr Blowers describes a very real problem in his article and no-one would want to pretend that there are quick or easy solutions. But I think it is important to see the other side of the picture which is the commitment and enthusiasm of many people in the health, social services and criminal justice systems-backed by government - to find ways of overcoming these difficulties. As I have tried to show, this has enabled substantial progress to be made already. We are committed to seeing it continue.

DEPARTMENT OF HEALTH / HOME OFFICE (1992/93) Vol 1 : Final Summary Report (Cm 2088); Vol 2: Service Needs (Reports of the Community. hospital and prison advisory groups): Vol 3: Finance. Staffing and Training: Vol 4: The Academic and Research Base; Vol 5: Special Issues and Differing Needs: Vol 6: Race, Gender and Equal Opportunities: Vol 7: People with Learning Disabilities (Mental Handicap) or with Autism. London: HMSO.

DEPARTMENT OF HEALTH (1992) The Health of the Nation: A strategy for health in England. Cm 1986. London: HMSO. - (1993) The Health of the Nation. Key Area Handbook Mental Illness. London: Department of Health.

JOHN REED, Department of Health, 133-135 Waterloo Road, London SE1 8UG

\section{Use of approval visits by the CTC}

Sir: I applaud the proposals that Roger Bullock makes in his recent article (Psychiatric Bulletin. April 1994, 18, 229) on the use of approval visits by the CTC. He does, however, suggest that the trainee member of a visiting approval team should be a CTC member. I am not a CTC member but had the opportunity to be the trainee representative on a CAPSAC team last year, making an approval visit to a scheme in the Wessex Region. I feel it enhanced my training by allowing me to take a senior role while asking a lot of questions. It continues to provide a perspective on the training I receive on my own scheme.

He states it is important for trainees to understand the approval visit process. There is perhaps no better way than going on a visit. It is itself a training experience and should remain avallable to interested non-CTC trainees.

LAURENCE SHELDON, St George's Hospital, Tooting, London SW17 OQT

\section{Hypnosis and psychotherapy}

Sir: Your correspondent (Psychiatric Bulletin, April 1994, 18, 246) is not fully informed. It is certainly sad that he has had to resort to tuition by unqualified 'therapists' in order to acquire a knowledge of hypnosis.

The British Society of Medical and Dental Hypnosis, Metropolitan and South provides regular courses of instruction for registered medical and dental practitioners to whom membership is restricted. Techniques of induction and the clinical uses of hypnosis are taught by a panel of fully qualified and experienced tutors.

Additionally there is a Section of Hypnosis and Psychosomatic Medicine within the Royal Society of Medicine and monthly meetings are held featuring speakers of international repute. There should be no problem for Dr Darwish "to get together and discuss potential uses and concerns" and such facilities have certainly been available for over 30 years.

DAvid WAXMaN, President, British Soctety of Medical and Dental Hypnosis, Metropolitan and South; and Vice President, Section of Hypnosis and Psychosomatic Medicine, Royal Society of Medicine, London WI

Sir: I do not agree that the College should be asked to accept that hyponosis should be considered as "additional therapy useful in that large area of illnesses which fall within the category of the neuroses ..." (Waxman, Psychiatric Bulletin, April 1994, 18, 247). But I believe that the College needs to take a firm stance on hypnosis and would make the following points.

(a) Hypnosis is a powerful tool and should not be left to unqualified or self qualified people to use or teach it.

(b) It is used in the treatment of cases that constitute a large part of the daily work of a psychiatrist.

(c) Patients ask for it a good deal and as most are denied it on the National Health Service they may seek it from people who may harm or exploit them.

(d) Because of the misconceptions engendered, the College should provide a consistent message about it.

Perhaps the College should encourage psychiatrists to become more familiar with hypnosis as it does with other forms of psychotherapy.

I would be happy to meet Dr Waxman and interested colleagues from the College to see how the College and the British Society of Medical and Dental Hypnosis can collaborate over these issues.

A.K. DARWISH, Brynffynnon Child and Family Service, Pontypridd, Mid Glamorgan CF37 4DD 